\title{
NIH wins patent on basic technique covering all ex vivo gene therapy
}

Washington. W. French Anderson, one of the pioneers of gene therapy, is at the centre of a new controversy following the announcement last week that the National Institutes of Health (NIH) have been awarded a broad patent covering one of the basic techniques in the field.

The patent, on which Anderson is the first named inventor (the other two are Steven Rosenberg and Michael Blaese), covers all ex vivo manipulations in which malfunctioning human cells are genetically altered to produce therapeutic levels of protein outside the body and then replaced.

Although the patent does not cover the alternative technique of in vivo manipulation - and is restricted to the United States - it is still sufficiently broad to have generated widespread comment. "Deep disbelief, I'd say that's what most people feel about the breadth of the patent," says Joseph Glorioso, head of the department of molecular genetics and biochemistry at the University of Pittsburgh. "This is analogous to giving someone a patent for heart transplants."

The patent is based on the first human gene therapy trial, carried out in 1990 by Anderson, Rosenberg and Blaese, all then at the NIH, and involving the treatment of a child with the rare blood disorder adenosine deaminase deficiency. "What we did was to provide proof in principle that gene therapy can work in humans," says Anderson. Since then, the technique is being developed as a potential treatment for disorder ranging from cancer to AIDS.

Since 1988, Anderson's work at the NIH has been co-sponsored under a Cooperative Research and Development Agreement (CRADA) by Genetic Therapy Inc. (GTI) in Gaithersburg, Maryland. As a result, the company now has an exclusive licence for the technology involved, and anyone commercializing an ex vivo gene therapy in the United States must negotiate a sublicence from the company.

Most research is exempt from this requirement. Even so, says Glorioso, the exclusive licence gives GTI considerable power. "They will be able to pick and chose winners in a very young field, and therefore to shape its development."

Anderson, who since 1991 has chaired GTI's board of scientific advisers, acknowledges that in principle this is true. But he points out that the US government, through the NIH, owns the patent, and that the company's licence is granted under a CRADA, which should ensure that it is made widely available.

Other patents are also pending. At the end of last week, Anderson and three colleagues from the University of Southern California in Los Angeles, where he now works, filed an application covering their in vivo gene therapy, although it is more narrowly focused than the patent just granted.

The patent granted last week, broad as it may be, is less wide-ranging that the original application, filed in 1989. That was for all gene therapy techniques, both ex vivo and in vivo. But, as frequently happens, this was whittled down by the US Patent Office. The last concession made by the applicants was to exclude the expression of marker proteins. Anderson says he accepted that concession - once GTI's lawyer had silenced his protests with a kick under the table.

But the company itself recognizes that the breadth of the patent could provoke a challenge. If so, a crucial set of documents will be the so-called 'file wrapper' containing the history of GTI's negotiations with the Patent Office. These will show whether the claim is as broad as it appears to be, and whether there are grounds for a challenge.

One lawyer who is already studying the dossier closely is Albert P. Halluin, a partner at Penney \& Edmonds in Menlo Park, California. Halluin is an attorney for the company Somatics, based in Seattle, which was

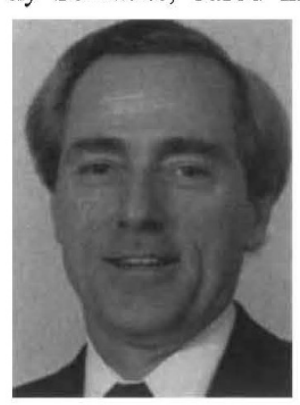

Anderson: provided first working proof. is trying to get a better understanding of the claim. As for what happens now to gene therapy and patents, he says: "We are all playing poker, and this is the first card turned up."

Given such uncertainty, there is no clear road map. Many leading participants, however such as Robert Abbott, president and chief executive of the gene therapy company Viagene, based in California, see a general shift from ex vivo to in vivo techniques.

All the current research in Anderson's laboratory, for example, is now in vivo. But ex vivo gene therapy is likely to remain important, even when in vivo techniques are developed. It may be some time before these are sufficiently advanced for companies to seek approval for therapies from the Food and Drug Administration.

Meanwhile, there is widespread acknowledgment that the patent is the first concrete evidence of an important shift in policy at the US Patent Office, announced last December, whereby patent examiners no longer demand extensive proof of the utility of an invention before issuing a patent.

Such a demand has been difficult for gene therapy researchers to meet, as the field is only now moving to efficacy trials. Uncertainty about whether patents would be granted has contributed to the recent reluctance among venture capitalists to invest in biotechnology companies.

"The patent office recognized the creativeness in this [ex vivo gene therapy] concept before the proof of efficacy, and that is good," says Jim Wilson, director of the Institute for Human Gene Therapy at the University of Pennsylvania, adding that the patent office's policy shift office will help attract some much needed capital into the biotechnology industry. Helen Gavaghan 